\title{
4 From cell culture to the molecular revolution
}

\author{
The rise of medical virology and its organization
}

\begin{abstract}
The electronics, radioactive isotopes, and complicated biochemistry of our age have threatened to turn medical science into something dangerously resembling technology. Now and again we need to be reminded of its fundamental biological elements. Against this background we express our admiration of the biological common sense, characterizing your approach to important medical problems, and of the wonderful simplicity of the solutions you have presented. - Sven Gard (1954) ${ }^{44}$
\end{abstract}

The history of science and medicine, especially in virology, has often privileged achievements in research laboratories over all other venues of scientific enterprise. This narrative slant is not entirely surprising because it is in these environments that the most dramatic and groundbreaking discoveries have taken place. It was argued among others by F.M. Burnet that around the midpoint of the twentieth century virology became an autonomous discipline based on its concepts, techniques and specific institutes that were created (1953a and 1953b). Later, historical research underpinned and reaffirmed this claim of growth to independence for virology (Méthot, 2016; Van Helvoort, 1993a, 1993b, 1994, 1996). The most useful breakthroughs in the field of virology that followed the initial spate of discoveries in the $1930 \mathrm{~s}$ occurred at university research institutes and laboratories of public health. As Marguerite Pereira, director of the PHLS Virus Reference Laboratory in the 1970 and 1980 os wrote, 'the history of virological discovery is therefore largely about technical innovation' (1986). Medical virology in the clinic hardly benefited from these technical advances until the end of World War II when easy-to-handle cell culture systems heralded a new era in virology. The present chapter depicts the steps forward in the second half of the twentieth century, and the accompanying organization of virologist networks across the Netherlands.

44 Presentation speech at the Nobel Prize Award in Medicine, 1954. The recipients of the prize were John F. Enders, Thomas H. Weller and Frederick C. Robbins 'for their discovery of the ability of poliomyelitis viruses to grow in cultures of various types of tissue' (Gard, 1954). 
It is not until the last quarter of the century that breakthroughs emerged in larger microbiology laboratories at general hospitals. There, practitioners of the nascent field of medical virology applied the newly discovered techniques and developed networks connecting microbiologists, immunologists and public health workers, so essential to their work (Bradstreet et al., 1964).

Although virology had its origins in bacteriology, diagnostic virology for the most part was not integrated in clinical bacteriology laboratories; the only exceptions arose due to the personal interest of certain heads of these laboratories. An obvious reason for this particular divide is that the activity of a virus-oriented laboratory was not of immediate value to the individual patient (Hawkes, 1979). Another explanation is the lack of technical equipment for and expertise in virology at the average bacteriology laboratory. This problem was solved in the United Kingdom by introducing members of the central PHLS Virus Reference Laboratory into the country's largest bacteriological laboratories in order to set up centres for virology, the so-called regional virus laboratories (Bradstreet et al., 1964).

This policy was not implemented in the Netherlands. Furthermore, because viral infections were not easily treatable until much later in the twentieth century, the initial focus of medical virology was on prophylaxis largely taken care of at public health institutes. For example, during the smallpox epidemic in Tilburg in 1951, only specimens of patients whose clinical diagnosis was not certain were submitted for laboratory diagnosis to the Institute for Preventive Medicine in Leiden, the Virus Laboratory of the National Institute of Public Health in Utrecht and the Laboratory for Hygiene in Amsterdam (Sas, 1954). In addition to common viral diseases of temperate regions, such as influenza, measles, rubella and mumps, a number of viral diseases - smallpox, yellow fever and dengue - were more prevalent in the tropics. Consequently, diagnostics and protective measures against these diseases, especially in the Dutch context, were assigned to the laboratories for tropical hygiene, which underwent significant administrative changes due to the political processes of decolonization after 1945 (see Chapter 7).

The progress of medical virology in the period covered in this chapter may be roughly characterized by three general waves: first, the successful culture of viruses in cell monolayers as described by John F. Enders, Thomas H. Weller and Frederick C. Robbins in 1949; second, the development of new immunologybased techniques, such as immunofluorescence, radioimmune assays and enzyme immune assays as well as negative staining methods in electron microscopy, during the 196os; and third, an era dominated by biochemistry and molecular biology, especially after the discovery of the polymerase chain 
Figure 14 John F. Enders (1897-1985)

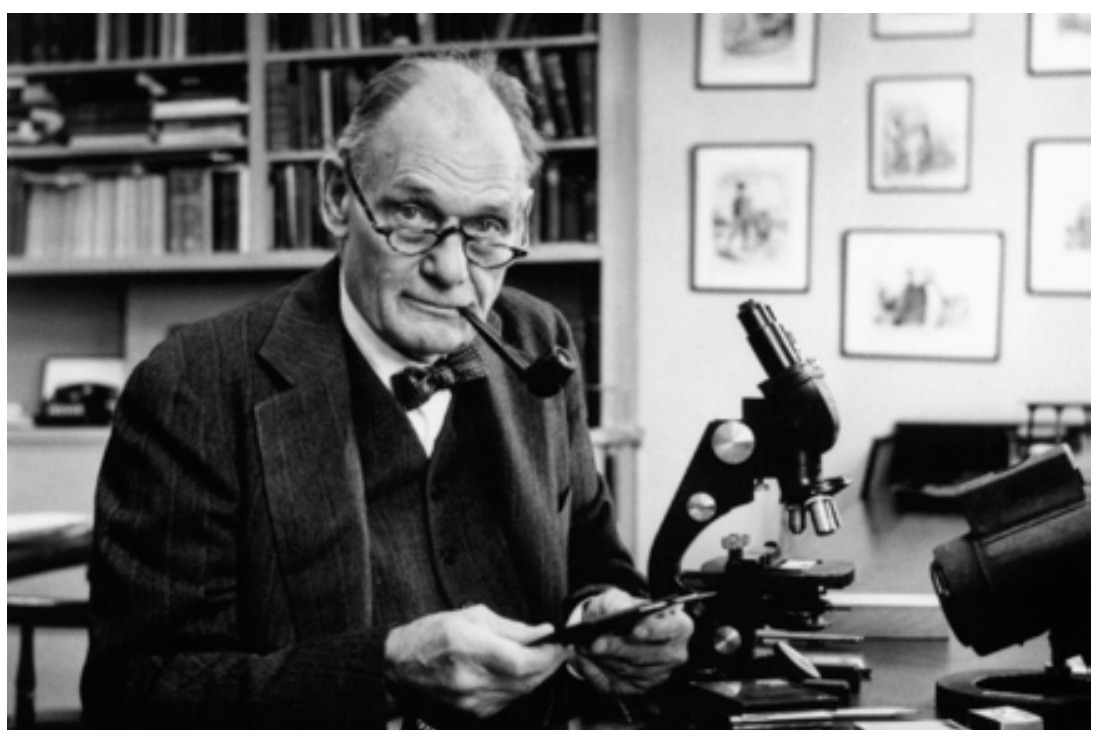

Reproduction courtesy of Harvard Medical School/G.Th. Diamandopulos

reaction by Kary Mullis (1944-2019) ${ }^{45}$ in 1983/1985. It should be emphasized that these different techniques did not necessarily compete with one another, of course, and that the advances in any one arena did not immediately replace existing methods. Rather, the developments acted synergistically to expand the investigative scope of the field of virology. It is beyond dispute that advances in fundamental molecular biology - e.g., insights into the structure of nucleic acids, the revelation of the genetic code - and the improved understanding of immunological processes were of tremendous importance for medical virology, but these subjects lie outside the scope of this book.

\section{The first wave: Virus culture}

Perhaps the single most significant hurdle in the advance of medical virology in the early part of the twentieth century was the inability to grow viruses in artificial media. Based on their experience from bacteriological research since the 1870 , microbiologists had been well aware of the vital importance of isolating and growing organisms in the laboratory for the advancement of their science. Indeed, in his 1954 presentation speech awarding the Nobel 
Prize in Physiology and Medicine to the trio of virologists, John F. Enders, Thomas H. Weller and Frederick C. Robbins, Sven Gard began by comparing the 75-year-old fight against bacterial diseases with the nascent fight against viral diseases with a glowing account of the numerous gains of bacterial cultures, pointing out that it was 'not difficult to find the reason why the virologists have failed where the bacteriologists were so successful. They have been severely handicapped by the difficulties connected with the cultivation of viruses' (Gard, 1954). Undoubtedly, the most pivotal breakthrough for isolating and growing animal viruses was the discovery of Enders, Weller, and Robbins, who developed techniques to grow monolayers of cells in continuous and semi-continuous cell lines in which they cultivated the Lansing strain of poliomyelitis virus (Enders et al., 1949).

As with many breakthroughs, serendipity and coincidence played a higher role than any concerted or systematic endeavour, in directing the three men towards their great success. As they recounted their venture upon receiving the Nobel Prize, it was in the course of working with culturing other viruses - mumps and varicella - and having a ready supply of a strain of poliomyelitis virus in storage that 'it suddenly occurred to us that everything had been prepared almost without conscious effort on our part for a new attempt to cultivate the agent' (Enders et al., 1954). Of note, only Robbins, who worked on rickettsia infections, had received training in the field of paediatrics - and hence had some familiarity with polio. Weller, who had been his roommate in medical school, had first specialized in helminthology, and later engaged in the field of virology as a research assistant to Enders, who, although the principal investigator, had originally begun his academic work studying literature (Weller and Robbins, 1991).

At the root of the difficulties that viruses posed for cultivation lay the property that set them apart from all other living creatures - their obligate parasitism in living hosts. Beijerinck had identified this property in his very first report on the tobacco mosaic disease, claiming that 'propagation results only when the virus is connected with the living and growing protoplasm of the host plant' (1942/1898, p. 39). But he could not offer insights into how said connections came about, and the theoretical implications of his observations were not considered for many decades. Meanwhile, however, whether or not they acknowledged or even recognized obligate parasitism, virologists had to accommodate this property in order to make any headway in their studies of viral infections. For many years, the only way scientists had to maintain the unknown and, until the 1930s, invisible agents of the infections of interest had been by repeated passages in susceptible host organisms. Especially in the case of human and animal viruses, this need for live hosts would prove a 
severe hurdle as animal facilities were expensive to maintain; as P.P. Laidlaw, the famous influenza virus pioneer, wrote with British humour: 'Man is an exceedingly bad experimental animal' (1935). The host specificity of many viruses - for many years the only way to propagate poliomyelitis viruses was in monkeys (see Enders et al., 1954) - meant that an animal facility was needed to keep different species for different studies, which increased costs further.

Although tissue culture had been attempted in non-virology context since the early part of the twentieth century, and the use of the enzyme trypsin to disperse cells from solid tissue had been described in 1916 by F.P. Rous and F.S. Jones, there was a long interval until the first successful inoculations of cell monolayers with viral specimens (Mortimer, 2009). The first successful attempts to culture viruses of multicellular eukaryotic organisms in an assayable manner emerged in the late 1920 s and early 1930 . In particular, the discovery that fertilized chicken eggs were a suitable medium for growing animal viruses represents an important stepping stone in the progress of medical virology (Woodruff and Goodpasture, 1931; Burnet, 1936). However, there remained many hurdles to virus cultivation in cell or tissue cultures. Microbial contamination of cultured cells challenged their inoculation with viruses. However, the discovery and use of antibiotics later enabled the maintenance of bacteria-free cultures. In parallel, the belief that tissues that would allow the propagation of viruses had to originate not only from animal species that were susceptible to the disease, but also from the organs targeted by the infection slowed down progress. Such an organotropic presumption was eventually invalidated by Enders, Weller and Robbins as they propagated poliovirus in various human embryonic tissues. From then on, far-reaching applications of the technique were realized at a fast pace. Within ten years of the seminal report, most of the cultivable animal viruses had been isolated in cell monolayers (Huebner, 1957, 1959). In 1948, a mere 20 human viruses had been recognized, of which only nine were established in the laboratory. In 1958, 70 additional human viruses had been established and studied in the laboratory. The culture of virus in cell monolayers also led to the production of a polio vaccine and the large-scale preparation of viral antigens for serological tests, which revolutionized the field of medical virology (see also Enders et al., 1954; Mortimer, 2009).

\section{First wave developments in Dutch clinical virology}

A 1953 publication by F. Dekking on the aetiology and laboratory diagnosis of viral diseases offers an overview of the viral diagnostic services offered 
in the Netherlands around 1950. At the time, Dekking was a virologist-to-be and researcher at the Laboratory for Hygiene in Amsterdam. He was later appointed to a chair in virology at the University of Amsterdam in 1968. In his inaugural lecture he called himself the second professor of virology in the Netherlands and R. Gispen the first as he was appointed in Utrecht in 196o. In comparison Michael Stoker became the first professor of virology at the University of Glasgow in $195^{8}$ - which was the first chair of virology to be established at a British university (Thomson, 1957; University of Glasgow, n.d.). Although ten laboratories offered viral diagnostics services in the Netherlands around 1953, Dekking noted that the Dutch were well behind in comparison to the UK and various Scandinavian countries. In particular, the lag in the implementation of cell culture techniques in the Netherlands was remarkable, even though a working group comprising of the NKI-AVL, SVOI and laboratories of histology, hygiene and anatomy at the University of Amsterdam had been set up as early as 1949 for the purpose of developing these technologies (De Bruyn, 1949). Even by 1953, according to Dekking's report, most Dutch laboratories were not equipped with adequate facilities for cell culture and had to rely on monkey inoculations for the isolation and culture of polioviruses. Nevertheless, Dekking expressed his optimism and high expectations over the reorganization of RIV, which entailed the establishment of a new virology laboratory, as well as financial assistance from the Dutch Health Organisation (TNO-NGO) ${ }^{46}$ for virus research.

The need for effective liaison and consultation channels between laboratories performing diagnostic tests and the clinicians who were submitting specimens for diagnosis was addressed by Dekking. While he acknowledged that specimens for certain routine diagnoses, e.g. of well-known or common diseases such as smallpox and psittacosis, ${ }^{47}$ could be submitted without prior consultation, he instituted a practice of mandatory advance consultation for all other diagnostic requests. Moreover, regardless of the disease, he insisted upon obtaining a résumé of clinical and epidemiological information about the specimens. He divided the diagnostic requests into two main categories: 1) those for the more routine diseases, such as variola, rabies as well as psittacosis and venereal lymphogranuloma, which were categorized as viral diseases at the time; and 2) those requiring more elaborate and specialized examinations. The latter included only about eleven viral diseases to begin with: vaccinia

46 Nederlandse Gezondheids Organisatie TNO (short) or Nederlandse Organisatie voor Toegepast-natuurwetenschappelijk Onderzoek ten behoeve van de Volksgezondheid (in full). 47 Diagnostic procedures for rickettsial and chlamydial infections were performed in viral laboratories because these organisms grow well in eggs and cell culture systems. 
Figure 15 F. Dekking (1913-2004)

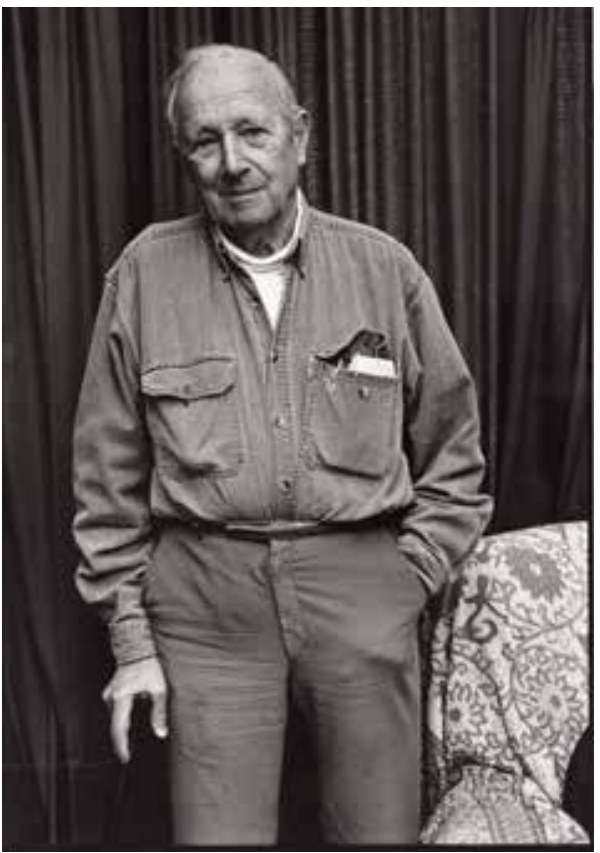

Photo: Henk Thomas, 1996

Reproduction courtesy of Allard Pierson, University of Amsterdam (154.515)

and cowpox, influenza, mumps, Newcastle disease (caused by an avian paramyxovirus), ${ }^{48}$ herpes, poliomyelitis, infection with Coxsackieviruses and neurotropic viruses, rickettsioses and Q fever, benign lymphoreticulosis (cat scratch disease), and yellow fever. Diagnostic tests for many viral diseases, such as measles, rubella, varicella, common cold, infectious hepatitis, and serum hepatitis, were not available in the Netherlands at the time of Dekking's report. He also dissuaded laboratories from the overenthusiastic collection of specimens for laboratory diagnosis, only to obtain negative results after many months of labour, and addressed the need for adequate information and collection of two serum specimens with an interval of two weeks to demonstrate a rise of antibody titres in the convalescence sample.

In many respects, viral diagnostics in the Netherlands followed the trends set in the UK a few years earlier. For instance, the isolation of poliovirus using cell cultures had been carried out at the Virus Reference Laboratory of the Public Health Laboratory in London in $195^{2}$ and at only a few 
laboratories of the Public Health Laboratory Service (PHLS) equipped to carry out such work by 1955 (Williams, 1985, p. 69). In the Netherlands, as indicated in a note in the Annual Report of the Regional Public Health Laboratory in Amsterdam, Dekking had introduced cell culture techniques at the Laboratory for Hygiene in 1955, although not for routine diagnostic purposes. Verlinde introduced cell culture at the laboratory of the Institute for Preventive Medicine in Leiden in 1954 after two years of pioneering (Verlinde and Kret, 1954). B. Hofman had been sent to the USA to gain experience (Versteeg, 1992). In Tilburg, Van der Veen initiated cell culture at the Regional Public Health Laboratory in 1955. The new technique had proved much useful during the polio epidemic the following year (Peeters, 2001). The cell culture media had to be prepared from scratch by suitably trained laboratory personnel, since only some defined components such as Eagle's or Earle's medium were commercially available. Importantly, the use of cells from a wide variety of human and animal organs allowed the discovery of a large variety of hitherto unknown viruses.

\section{The second wave: Immunological and visualization techniques for rapid detection}

After virus culture techniques, the developments that had significant impact on viral diagnostics occurred in the discipline of immunology and as technical improvements in visualization techniques. The increased understanding of the nature and specificity of immune reactions - for instance, involving different types of immunoglobulins such as IgG and IgM - enabled scientists to produce and use a range of specific antibodies for various diagnostic purposes. The principle of the fluorescent antibody technique that was introduced in the 196os was a combination of an antigenantibody reaction, in which the antibody is bound to its homologous antigen, and of the labelling of the antibody with a fluorescent dye which can be made visible by excitation with an appropriate light wavelength (Gardner and McQuillin, 1980). The application of immunofluorescence for rapid virus diagnosis was meticulously described by Philip Gardner and Joyce McQuillin from Newcastle upon Tyne, UK. Using this technique, the presence of virus could be demonstrated in clinical specimens, for instance, upon respiratory infections. By the use of fixed or unfixed virus-infected cells, specific antibodies could also be detected in serum specimens.

In 1975, Köhler and Millstein were able to create immortal cell lines called hybridomas that could rapidly produce specific single (or monoclonal) 
antibodies (Köhler and Milstein, 1975). The production of monoclonal antibodies in vitro was a giant step in diagnostics, due to the much-defined specificity of such antibodies for an antigen - in this case, a specific viral component. Monoclonal antibodies could be used in serological assays, for rapid virus detection in cell culture, or for viral antigen detection in clinical specimens.

The 1970 s and 1980 s were dedicated to the development of the enzyme immunosorbent assay (EIA), also called enzyme-linked immunosorbent assay (ELISA) (see Chapter 6 for the specific role of Dutch contributions in the development of ELISA techniques). The technique built on principles used by radioimmunoassay was developed in the 196os; here, the reaction between a radiolabelled antigen and a specific antibody was measured by following the competition between radiolabelled and unlabelled antigens. This measurement involved a separation step between bound and free-labelled antigens. Elaborating on this concept, it was found that separation could be increased by immobilizing the antibody or antigen on a solid phase, such as plastic. The use of enzymes instead of radioisotopes was later exploited as a marker (Kemeny and Challacombe, 1988). A variety of enzymes has been used, such as horseradish peroxidase or alkaline phosphatase. All these techniques dramatically reduced the time needed for individual diagnosis and allowed the instalment of screening programmes.

Electron microscopy became more frequently applied to clinical virology, when S. Brenner and R.W. Horne described in 1959 the application of the negative staining method as a simple technique for the study of virus particles in suspension. At the same time, methods for embedding tissues for thin sectioning improved. The combination of both techniques revealed excellent information on viral structure (Field, 1986). Uncultivable viruses, such as the noroviruses, Norwalk viruses, and astroviruses, could be detected by this technique. The technique proved also useful in the rapid distinction between smallpox and chickenpox. Possibly due to the barriers posed by the expensive costs of obtaining and maintaining the instruments, however, these methods were not widely used in the routine and rapid isolation of viruses. As a result, S.S. Biel and H.R. Gelderblom, both recognized experts at the Robert Koch Institute in Berlin, had to heave the following sighs: Starting in the 199os and coincident with the broad introduction of 'modern' diagnostic techniques, the number of electron microscope (EM) diagnostic labs has decreased considerably - in spite of the obvious advantages of this technique (Biel and Gelderblom, 1999). Another passionate plea for electron microscopy in clinical virology was made by S. Biel and D. Madeley 
during the European Virology Meeting in Glasgow in 2000. Nevertheless, the application of this technique likely will play a greater role in virus research than in routine viral diagnosis (Biel and Madeley, 2001).

\section{Second wave developments in Dutch clinical virology}

Perhaps our best source of information about the state of the art in Dutch viral diagnostics during the second wave is a 1975 article by Jacoba G. Kapsenberg published in the NTvG. An internationally recognized expert on enteroviruses who was responsible for viral diagnostics at the National Laboratory of Public Health (1954-1989), she was also later the author of a chapter on enteroviruses in a definitive handbook on infectious disease diagnostics (Lennette et al., 1988). In her 1975 article, Kapsenberg described new immunological and microscopic techniques, with specific details on their application to viral diagnostics. Published some two decades after Dekking's report, Kapsenberg's paper needed much less time and space to enumerate the viruses that could not be propagated in cell culture and therefore, could only be visualized by electron microscopy. The list included molluscum contagiosum, hepatitis A, hepatitis B, epidemic gastroenteritis, and human oncornaviruses. The human parvovirus B19, described in 1975 by Y.E. Cossart as the causal agent of the fifth disease (occurring mostly in children), was not yet included in the list. However, their diagnosis continued to be challenging, because only a handful of laboratories in the Netherlands had their own electron microscopes; multiple laboratories, both within universities and at RIVM, had to share one instrument.

While the serological detection of specific antibodies was performed by immunofluorescence or enzyme immunosorbent assays, older methods, such as complement fixation assay, immunoprecipitation, and hemagglutination inhibition assays, maintained their value during the second wave. In parallel, the propagation of viruses in animals and tissue culture was replaced for the most part by monolayer cell culture using trypsin to disperse cells from tissues and standardized nutrient media with addition of antibiotics. Other technical advances included the improvement of cooling techniques, of the homogenization of tissues, of microscopes, ultracentrifuges, ultrafiltration, and mechanization and the use of micro-instruments for serology. The availability of these new techniques enabled larger hospital-based bacteriological laboratories to perform virological serology testing and direct detection of virus antigen in clinical specimens, for example, the detection of respiratory syncytial virus in nasopharyngeal fluid. 
In the intermediate period between the second and third wave, modifications of cell culture techniques were developed that yielded more rapid results. Soon after the publications of Griffiths et al. in the UK on rapid cell culture techniques consisting of a centrifugation step to enhance the contact of the specimen onto the cell monolayer and an early detection of presence of virus amplification by immunofluorescence. These methods were introduced at Groningen, Rotterdam, and at a number of other virology laboratories across the Netherlands (Griffiths et al., 1984; Rothbarth et al., 1987 and 1988; Schirm et al., 1987; Schirm et al., 1992). They became methods of choice for the diagnosis of cytomegalovirus (CMV) and respiratory virus infections because of their high sensitivity, specificity and result-yielding rapidity (Stirk and Griffiths, 1988). The diagnosis of CMV infection in transplant patients could be made much earlier and altered the clinical management of CMV infection in these immunocompromised patients (Griffiths et al., 1984). These methods later became less important when many laboratories downgraded virus isolation methods in favour of molecular techniques around the turn of the twentieth century (Jeffery and Aarons, 2009; Niesters, 2002).

\section{The third wave: The molecular revolution}

Without a doubt, the single most dramatic and influential technical advance in molecular biology that occurred in the early 1980s was the development of the polymerase chain reaction (PCR) by the biochemist Kary Mullis (1993). These advances built on the long history of the molecular chemistry of the gene (Booss and August, 2013, p. 294). In the 1970s, hybridization techniques proved to be useful to study viruses that could not be grown in tissue culture (Clewley, 1986). Other methods that were applied in virus research were among others recombinant DNA technology, oligonucleotide fingerprinting of RNA viruses, restriction mapping of double-stranded DNA, electrophoretic migration patterns, Southern, Northern, and Western blotting, and, last but not least, genetic sequencing. Although these techniques had been developed earlier than the PCR, they were not applicable to routine viral diagnostics. The PCR technique broke this barrier because it allowed the rapid and automated amplification of even minute quantities of viral DNA or RNA in a specimen, which could then be detected easily using standard diagnostic techniques, without the need for growing them in culture. Various refinements and improvements of the technique and instruments as well as associated methods, such as digital processing and information technology, accelerated the widespread use of PCR. Despite hurdles posed 
by problems of cross contamination of specimens and reagents due to the overly rapid generation of large amounts of amplified material, the method quickly became a part of the stock arsenal of both diagnostic and basic research laboratories worldwide. It is no small measure of the success of the technology that just a decade later Mullis was awarded his share of the 1993 Nobel Prize in Chemistry for his invention of the PCR technology.

The rapidly developing nucleic acid-based techniques resulted in a big shift in technical methods used in diagnostic virology laboratories (Persing and Landry, 1989). The presence of human immunodeficiency virus, of hepatitis B virus, of hepatitis C virus (at the beginning of the 199os) and of other clinically important viruses could be demonstrated in specimens that were negative by the then widely used cell culture techniques. Implementation of the first PCR tests was accompanied by challenging problems of contamination with nucleic acids produced in high numbers by the reaction, resulting in the dire necessity for separate working rooms. An important step forward for diagnostic virology and the management of patients was the development of quantitative molecular assays. Monitoring of viral genome quantities has now become part of most clinical management programs, e.g., to assess the success of antiviral therapy.

\section{Third wave developments in Dutch clinical virology}

If there is one area in medicine where virology preceded bacteriology, it would be in the development and implementation of molecular diagnostics. Again, this trend is not surprising, considering that bacteriology relied on tried and tested methods that had been in existence for a long time, compared to virology, which developed alongside molecular biology with the use of molecular assays for the detection of such difficult and non-cultivable viruses as human immunodeficiency virus, hepatitis $B$ and $C$ virus, and human papillomaviruses. Over the late 1980 s and in the 1990s, molecular tests were developed and used not only at university diagnostic laboratories or in Groningen at the laboratory of the Municipal Health Service that performed routine clinical diagnostic work in virology for the Academic Hospital, but also at laboratories of RIVM, the Central Laboratory of the Blood Transfusion Service of the Netherlands Red Cross, ${ }^{49}$ the laboratory of the Foundation Cooperating Delft Hospitals, and at Organon Technica (see Chapter 6). 
The number of general medical microbiology laboratories with virology diagnostic facilities that used serology and nucleic acid detection assays - based on the wide availability of commercial test kits - had expanded substantially by the turn of the twentieth century. Concurrently, virus isolation by cell culture lost ground in the daily diagnostic practice, but did not disappear altogether, remaining mainly in some university centres as the preferred methodology for propagating viruses for phenotyping and drug susceptibility testing. Application of multiple PCRs for the detection of respiratory viruses replaced rapid viral cell culture tests that were introduced in the 1980s. A financial factor might have also played a role in the rather early introduction of molecular tests in Dutch diagnostic laboratories. In 1996, the COTG, ${ }^{50}$ the official body fixing prices in the health sector, approved to charge reasonable tariffs for the refund of these tests.

In parallel, the range of serological tests applied for virological diagnostics changed over the course of the third wave. While in the 1980s, the complement fixation test was carried out at most virological laboratories, a rapid trend towards the use of EIA/ELISA tests and automated instruments could be observed in the last two decades of the twentieth century.

\section{Public health laboratories and medical virology}

The involvement of central public health services played a key role in the establishment of diagnostic virology networks worldwide. As noticed by Dekking, the virology laboratory of the National Institute of Public Health (RIV) was central to the development of medical virology in the Netherlands, but in fact, a similar pattern occurred more widely, in other European countries as well as the United States (Bradstreet et al., 1973; Williams, 1985). According to a 1976 summary report by the European Office of the World Health Organization, countries with a federal system of government (Germany, Austria, Switzerland, Yugoslavia) had by this time, some form of a centralized system - for instance, an institute for epidemiology and microbiology - which ordinarily provided reference services, similar to those provided by the PHLS in the UK (Williams, 1985, p. 165). In the Netherlands, the RIV Central Laboratory maintained a policy of contracting out some of its reference services to university or other specialist laboratories. Nevertheless, Dekking made an appropriate remark on the role of RIV with regards to medical virology. In countries such as France, Germany, Italy, and Belgium, 
the central institutes had no formal links with the peripheral laboratories apart from the provision of reference services and quality assessment.

The United Kingdom's Public Health Laboratory Service (PHLS) deserves a special mention for its pioneering role in anchoring and shepherding the nascent field of medical virology in its early years. Like many other national public health establishments, its virological work was limited at first to smallpox diagnosis, especially during the early part of the twentieth century. But in 1946, it became one of the first organizations of its kind to establish a dedicated Virus Reference Laboratory (VRL) (Bradstreet et al., 1964; Bradstreet et al., 1973). The VRL was established with a staff of only one qualified virologist and one technician, and expanded by $195^{\circ}$ to a staff of four virologists, who offered diagnostic - mainly serological - services for an array of diseases caused by viruses and similar agents: influenza, psittacosis-lymphogranuloma-venereum group, Q-fever, the pox group, lymphocytic-choriomeningitis virus, mumps virus and primary atypical pneumonia. Cell culture techniques were used from 1954 onward. In 1956, the VRL introduced its members into bacteriological laboratories at its various regional offices, to set up autonomous centres for virology at these locations, thus laying the foundations of a professional network. By 1970, this network had grown to include ten regional laboratories, each with a consultant virologist and nearly 6o so-called area laboratories engaged in virology in addition to bacteriology (Bradstreet et al., 1973). In 1967, J.E. Banatvala and his colleagues at the St Thomas Hospital published a report of their experiences in clinical virology, in which they stressed the importance of laboratories such as their own, which, as an integral part of a research department of a teaching hospital, provided specialized expertise rather than comprehensive services. Meanwhile in her 1986 overview of '40 years of virology in the PHLS', the then-director Marguerite Pereira highlighted the range of immunological techniques that were in routine use for virological diagnostics by the 1970s.

In Germany, medical virology seems to generally be provided in university laboratories rather than in public health laboratories. Klaus Munk published in 1995 a detailed history on the development of virology in Germany in which he stated that nearly all of the listed 37 university virology institutes provided also medical/clinical diagnostic virology services besides their research activities (Munk, 1995). Two out of a total of fifteen non-university centres where virology emerged belonged to pharmaceutical companies, another two were government veterinary laboratories, one was the military virology laboratory, and another one was a primate centre. Among the remaining nine centres were the famous Robert Koch Institute in Berlin, the 
Paul Ehrlich Institute in Frankfurt am Main, the Bernard Nocht Institute in Hamburg, the Max Planck Institute in Martinsried, and the Institute for Molecular Virology of the GSF/Research Centre for Environment and Health in Neuherberg. Therefore, from this overview, it may be concluded that in Germany, medical virology and diagnostics occurred in the early years primarily through activities carried out at university laboratories rather than in public health facilities.

In France, medical virology seems to have been omitted from discussions on historical overviews of French medicine and medical science. A surprising example of this is Claude Chastel's excellent Histoire des virus, de la variole au SIDA (1992), which does not provide any specific overview of the development of medical virology in public health or university laboratories in France. In any case, the Institut Pasteur was the stimulating ground for virology in France (Chastel, 1992; Girard, 1988). Nevertheless, six of the eleven authors of the first edition of a French standard work on medical virology entitled Diagnostic des maladies à virus came from all over France and were associated with sections of the National Laboratory of Public Health (Sohier, 1964). It may appear as ironic that one of the authors was Chastel himself; his affiliation being the Medical Faculty in Brest, where he was also biologiste des hôpitaux.

In the USA, the early years of diagnostic virology were recently described by J. Booss and M.J. August (2013, pp. 158-196). The availability of virology laboratory diagnostics was as limited as in Europe. Epidemiologic studies were conducted by a variety of federal, state, and university-based hospital laboratories. For example, an interesting overview of such studies on virus infections within families is given by J. Fox and C.E. Hall (1980). Diagnostic virology laboratories were located at public health laboratories and university hospitals (Booss and August, 2013, p. 158). In general, virology diagnostics services were provided by hospital-based bacteriology laboratories much later, from 1970 onward, due to the need for highly specialized technical and diagnostic expertise. The techniques that were used consisted of virus isolation and identification techniques, and serological tests revealing the presence of virus-specific antibodies. A lively debate at a 1947 Symposium on Virus Diseases of the Pathology and Physiology section at the $96^{\text {th }}$ annual session of the American Medical Association offers a good snapshot of the status of the field. Stanford University-based Edwin Schultz pointed out that whereas diagnostic procedures had advanced considerably over the preceding decade, they were for the most part highly specialized and out of reach of the ordinary clinical laboratory (1948). The well-known American virologist Edwin Smadel of the Army Department of Virus and Rickettsial 
Diseases also warned that the procedures employed in virus diagnostics were still so highly specialized that it required competent research workers to perform the assays in a satisfactory way (Smadel, 1948). He wrote: 'These research procedures are not the physician's to demand for use in routine diagnostic work. Rather they are the physician's to request only, and then in an investigation in which he cooperates with the laboratory worker. If the physician fails to employ these research procedures wisely, he is wasting the common investment in the advancement of medicine' (1948, p. 1079). The laboratory of the Army Medical Department School and that of the National Institute of Health performed regularly all or the great majority of the available tests. The state and municipal laboratories performed some of the diagnostic procedures while a number of laboratories associated with teaching institutions performed but a few of the tests.

\section{The basic and the applied: Separate or joint ways of organization?}

Although virology gradually blossomed from the 1950 s onwards to become a unique discipline requiring specialized skills and knowledge, it remained within the confines of microbiology. With the growth of the discipline to maturity in the $1960 \mathrm{~s}$, workers in the field felt the necessity to meet independently as virologists. At the same time, however, even the field of virology itself was driven by investigators with different interests, such as fundamental virology, plant virology, veterinary and human virology. The endeavours pursued by virologists of these various fields were separate, yet joint at the same time. As the boundaries between these fields were not sharply drawn, it is not surprising that some of the virologists played a role not only in medical virology but also in fundamental or veterinary virology.

\section{Dutch Societies and medical virology}

\section{The Netherlands Society for Microbiology}

The first Dutch general microbiology organization was the Netherlands Society for Microbiology (NVvM),,$^{11}$ established in 1911, with Beijerinck as its first chairman. Over the 196os, members of the NVvM who were interested

$5^{1}$ Nederlandse Vereniging voor Microbiologie (NVvM), and since 2011 Koninklijke Nederlandse Vereniging voor Microbiologie (KNVM). 
in virology organized informally their own so-called Dutch Virology Day. Unfortunately, the early history of this event remains obscure due to the paucity of archival and oral history records, but some of the early figures involved in convening the 'Virology Days' included well-known representatives from different branches of virology: F. Dekking, R. Gispen, and J. van der Veen in the field of medical virology, J.D. Verlinde in the field of both medical and animal virology, and J. van der Want in the field of plant virology. The first written communication that could be found in the archives of the NVvM is a letter from Verlinde (1969a) dated 18 March 1969 and addressed to the executive committee of the society. It reported on the success of the 'Virology Days', and on the preference of the coordinators to manage their organization independently of the NVvM, because non-members of the society were also regular participants. Verlinde further assured not to intervene with the program of the upcoming autumn meeting of the society.

Around 1970, this group of virologists informally formed the Virology section of the NVvM, to organize the 'Virology Days' as well as symposia on matters of common interest. Eventually, in 1977, after years of discussion on the desirability of sections within the $\mathrm{NVvM}$, the group became one of five official sections of the society, responsible for all subfields in virology, including medical, plant, and veterinary virology. Members of the executive committee of the Virology section were: veterinary virologist M.C. Horzinek, molecular biologist A.J. van der Eb, medical virologist A.C. Hekker, and plant virologist D. Peters. Under the enthusiastic guidance of M. Horzinek, the annual Virology Days were maintained and organized at first by P. van der Marel and after 1983 by H.G.A.M. van der Avoort, both working at RIVM (H.G.A.M. van der Avoort, personal communication, 2017). In 1992, the organization of the 'Virology Days' was turned over to P.J.M. Rottier and R.C. de Groot, at the Veterinary Faculty of the University of Utrecht (P.J.M. Rottier, personal communication, 2018). Under this new management, the 'Virology Days' were renamed 'Dutch Annual Virology Symposium' (DAVS). The format of the meetings included presentations by invited speakers for each of the four disciplines - at least one of these speakers was invited from abroad - and by other participants selected through a review of submitted abstracts. Although the expressed aim of the DAVS was to present research subjects covering all areas of virology, there was a perceptible shift in emphasis to fundamental rather than medical and other applied aspects of virology.

From 1999 to this day, the DAVS has been held at the Royal Netherlands Academy of Arts and Sciences in Amsterdam; the Beijerinck Virology Fund of the Academy allows inviting distinguished foreign keynote speakers; 
while the Veterinary Faculty of the University of Utrecht continues to offer secretarial support. The Beijerinck Virology Fund was founded in 1965 by L.E. den Dooren de Jong and his wife, A. den Dooren de Jong-Ris, to honour the memory of Beijerinck, who was his teacher and friend. ${ }^{2}$ The fund awards the prestigious Beijerinck Virology Prize every two years to an internationally renowned researcher in the field of virology (Van Kammen, 2011). Certainly, these honours belong to Beijerinck's beneficiaries.

\section{The Netherlands Society for Medical Microbiology}

The professional society for medical microbiologists in the Netherlands is the Netherlands Society for Medical Microbiology (NVMM), ${ }^{53}$ which was established in 1992 and considered the successor of the pre-existing Netherlands Society of Laboratory Medical Doctors, ${ }^{54}$ founded in 1950. This professional society initially regrouped medical doctors engaging into clinical chemistry and clinical microbiology, as well as pathologists until the establishment of their own professional society in 1955. The Science Committee of the NVvM in which each division has a representative, is a link between all divisions, including the medical microbiology division i.e. the NVMM, and it annually organizes a joint scientific meeting on the field of microbiology at large, meant to build bridges between the different communities of microbiology scientists. Over the 1990s a virology session was organized at the joint meeting by the Dutch Working Group for Clinical Virology55 in collaboration with the Virology section of the NVvM.

\section{The Dutch Working Group for Clinical Virology}

A small group comprising an epidemiologist and medical virologists at the National Institute of Public Health (RIV) in Bilthoven was responsible to form the Dutch Working Group for Clinical Virology. The commencement of the working group is not documented on paper and therefore this narrative is mainly based on interviews with Jacoba G. Kapsenberg - known to her intimate colleagues as Cootje. She has vivid memories of those early years. The impetus of the working group was given by epidemiologist M.F. Polak,

$5^{2}$ https://www.knaw.nl/nl/prijzen/prijzen/knaw-beijerinck-prijzen-voor-virologie, latest access August 2019.

53 Nederlandse Vereniging voor Medische Microbiologie (NVMM).

54 Vereniging van Laboratorium Artsen (NVLA).

55 Nederlandse Werkgroep Klinische Virologie (NWKV). 
who moved in 1960 from the Laboratory for Hygiene in Amsterdam to RIV. In 1964, he took the initiative to collect and analyse monthly data from five virological laboratories (Stenfert Kroese, 1999). Polak invited representatives from each of these laboratories to meet once a month at Bilthoven, to review the summarized compilation of the collected epidemiological data. The laboratories involved were: the Laboratory for Virology at RIV, the virology laboratory of the Netherlands Institute for Preventive Medicine at Leiden University, the Laboratory for Hygiene at the University of Amsterdam, the Regional Public Health Laboratory at the Municipal Health Service of Rotterdam, and the Regional Public HealthLaboratory at the St Elisabeth Hospital in Tilburg. The country's leading virologists - all of those main characters who have already been mentioned - participated in these meetings. J.D. Verlinde from Leiden, F. Dekking from Amsterdam, G.J.P. Schaap from Rotterdam, J. van der Veen from Tilburg/Nijmegen, and, in addition to Polak, R. Gispen and J.G. Kapsenberg from Bilthoven. Not surprisingly, later on four of them were also members of the steering committee of the Virology section of the NVvM. In 1967 and 1970, respectively, N. Masurel from Rotterdam and J.B. Wilterdink from Groningen also joined the meetings. In addition, as the importance of an applied or 'translational' approach to infectious diseases was already well understood, representatives of the Laboratory of Virology at the Veterinary Faculty of the University of Utrecht were also invited (M.C. Horzinek, from 1971 onward). In the 1970s, maybe under the influence of the general democratization of the universities, the meetings became open to non-medical academic staff members of the above-mentioned laboratories.

As indicated, one of the main points on the agenda of the meetings of the working group was to review monthly epidemiologic reports. In addition, items such as technical problems faced by laboratories, the availability of reagents, e.g. antigens and specific antibodies, as well as individual clinical cases, were discussed. Regrettably, however, we were unable to find any records of the meetings over about the first 20 years of the working group.

The system for collecting monthly data on acute virus infections was similar to that instituted at the Public Health Laboratory Service (PHLS) in the United Kingdom. Since the early days of World War II, the UK's public health laboratories, as well as (since 1951) many hospital laboratories outside PHLS, were expected to submit detailed weekly reports on the infectious diseases diagnosed by the laboratory to the central Epidemiological Research Laboratory (ERL) in London (Bradstreet et al., 1964; Bradstreet et al., 1973; Pereira, 1986, p. 10). Based on these reports, the ERL prepared a weekly summary of diagnosed acute infections for wide distribution. The near real-time 
availability of laboratory results meant that acute virus infections of the respiratory tract or nervous system, in particular influenza and poliomyelitis, were kept under the strictest possible surveillance. The main difference between the British and Dutch systems was that of scale. According to Patricia

Bradstreet, in addition to the Central Public Health Laboratory (Colindale, London), where she was appointed director of the Standards Laboratory for serological agents in 1956, nine area laboratories and more than 40 regional laboratories across England and Wales were involved in virology work in 1964. In contrast, in the Netherlands, only the five aforementioned laboratories cooperated in the reportage system. Nonetheless, the small number of virology laboratories in the Netherlands as well as smaller distances between them afforded more opportunities for frequent and personal meetings. Their regular meetings allowed rapid communication among experts as well as prompt deployment of well-conceived public health measures based on international knowledge and individual expertise. All Dutch virologists had international contacts both through personal channels and through more formal institutions such as the World Health Organization (WHO). In the early 1950s, the Netherlands Institute for Preventive Medicine in Leiden was designated as the WHO Influenza Centre for the Netherlands (Bijl, 1954). In 1969, RIV was acknowledged as an 'International reference institute for smallpox vaccine control' of the WHO (Van Zon, 1990).

\section{Expansion of the working group}

In the 1970s, the number of general hospital-based microbiology laboratories which provided diagnostic virology laboratory services, increased. As a result, staff members of these laboratories, responsible for viral diagnostics, were invited to take part in the working group. In the early 1980 , residents in medical microbiology were allowed to attend the meetings. After lengthy discussions, the meetings were eventually open to senior technicians as invited guests. By the 1990s, biochemists had gradually made their entry into the diagnostic virology laboratories, initially staffed mainly by medical microbiologists. In 2011, all eight university hospitals, RIVM and fourteen general hospital-based laboratories were represented by medical microbiologists and scientific staff members, mostly of the field of medical molecular biology (the latter discipline indicating that virology had indeed entered its molecular - third - wave).

\section{Working group meetings}

By 1980, the meetings of the working group were organized three times a year by a formal steering committee. A scheme rotating the meeting venue 
through each of the member laboratories was instituted and remains in place to this day. Meetings typically start with a discussion of routine business and administrative matters, followed by reports of the RIVM liaison officer and since 1997, reports of the liaison officer of the European Society of Clinical Virology (ESCV). Regular items included discussions on the external quality assessment scheme of the Foundation for the Quality Control of Medical Microbiology (SKMM) ${ }^{5}$ and later of Quality Control for Molecular Diagnostics (QCMD). Usually, there was a presentation on the research program performed at the hosting laboratory. The agenda for the latter part of the day varied, featuring major as well as more limited virological or technical topics, relevant epidemiological figures, and case reports. The time scheme offered plenty of time for discussions and for the airing of controversial topics. The main themes concerned basic approaches to the diagnosis of viral infections, choices of tests employed, choices of specimen, interpretation of test results, epidemiology, vaccination, and the increasing possibilities of antiviral therapy. Topics of perennial interest - persisting to the present day - include diagnostics of emerging infections, collection and transport procedures for specimens that may contain dangerous pathogens, and the safety of the working environment. As part of permanent education, keynote speakers were invited to deliver lectures on specific subjects. In the 1980 s, increasingly more attention was paid to the application of molecular methods in medical virology, such as in situ hybridization and later nucleic acid amplification techniques. In the 1990s, antiviral therapy became of age, enlarging substantially the equipment to fight viral infections. Several sessions of the working group meetings were then devoted to chemotherapy of viral infections caused by human immunodeficiency virus, hepatitis $B$ virus, hepatitis $C$ virus, cy tomegalovirus, Epstein-Barr virus, and herpes simplex virus, among others.

\section{Epidemiological reports}

According to Jacoba G. Kapsenberg, RIV received in 1979 the WHO's invitation to file monthly epidemiological reports on all laboratory-confirmed cases of viral infections, including such information as virus name, detection methods, confirmation tests, comprehensive clinical anamnesis, and patient age and gender. RIV staff members went to great length to compile the reports from data obtained from all virology laboratories in the Netherlands that were at that time members of the working group (Kapsenberg, 2002). Despite these efforts, the international endeavour proved unsuccessful; there were too many laboratories in too many countries that could not send regular or detailed 
enough reports. For individual virology laboratories, preparing these reports significantly increased staff workload, due to the need for detailed data and frequent lack of clinical information. This resulted in delays in reporting or even cessation of reporting on a monthly basis, by the contributing Dutch virology laboratories. Obviously, this trend also occurred elsewhere. By the beginning of the 1980 s, only the United Kingdom, Israel and the Netherlands sent consolidated monthly reports to WHO (J.G. Kapsenberg, personal communication, 2015). RIV continued to maintain the reporting system to support the field of medical virology with all new information on viral diseases that could be generated by the community of Dutch clinical virologists and clinicians.

In 1985, J.M. Ossewaarde at RIVM initiated the design and development of a computer programme to facilitate input and maintenance of the epidemiological data. Data had to be sent on a floppy disk to RIVM as the internet was not yet in existence. But the programme proved to be premature for the majority of laboratories. In 1989, A.M. van Loon, then head of the RIVM Laboratory for Virology, proposed and organized a change from monthly to weekly epidemiological reports that included much less clinical information. Following a series of lengthy discussions, a new system of weekly reports containing nothing but laboratory results was introduced in the mid-199os. Reports were faxed to RIVM, where they were further processed using a computer programme designed by P.M. Schrijnemakers. The system evolved from fax- to internet-based, and was communicated in the form of spreadsheets. Nowadays all virology diagnostic laboratories submit weekly epidemiological reports to RIVM. The received data is analysed and compiled into the electronic report Weekly Reviews of Infectious Diseases Signals, ${ }^{57}$ which is available to all Dutch professionals working in the field of infectious diseases. The number of epidemiological reports has not ceased to increase, probably due to increases in the number of specimens examined and/or due to the use of more sensitive techniques. This reporting system has nevertheless some limitations, for example, because laboratories only report positive specimens. As a result, only the numerator and not the denominator of reported viral infections are known. However, the aggregated data from 23 nationwide laboratories are sufficiently reliable to rapidly show epidemiological trends in viral infections. Despite the absence of detailed clinical and epidemiological information, outbreaks of viral diseases can be assessed. If detailed information is required, special surveys are prepared and performed. Since the establishment of the National Coordination Structure for Infectious Diseases (LCI), ${ }^{58}$ which provides guidelines on how to 
record data during suspected epidemics using standardized formats, in 1994, results of the surveys are made available to all health professionals, including clinicians and laboratory and public health workers.

\section{Professionalization}

Although Polak had initiated the meetings in 1964, it was not until 26 September 1989 that the status of the working group was formalized as the Dutch Working Group for Clinical Virology with the introduction of a set of regulations. A.M. Dingemans-Dumas was appointed chairperson at this time. The stated aims of the working group were the promotion of virus diagnostics and of the study and management of viral infections in humans, including epidemiology and immunology. The regulations were modified in 2001 in order to integrate the working group within the Netherlands Society of Medical Microbiology, which necessitated the revision of the by-laws of the latter since until that time the society had no provisions for including working parties. By 2011, the working group meetings had representatives from all eight university hospitals in the Netherlands as well the RIVM and fourteen general hospital-based laboratories.

\section{Standardization and external quality control}

In 1981, virology diagnostic laboratories in the Netherlands began to participate in a national external quality assessment scheme led by the Foundation for the Quality Control of Medical Microbiology (SKMM). ${ }^{59}$ This foundation had been established the same year by medical microbiologists convinced of the value and necessity of such a system. In 2005, the SKMM merged with the Foundation for the Quality Control of Medical Laboratory Diagnostics ${ }^{60}$ (SKML), a Dutch consortium including participants from laboratories of clinical chemistry, medical microbiology, pathology, haematology as well as clinical pharmacy.

Meanwhile a similar initiative for an external quality scheme for molecular tests was undertaken at the European level. One of the founders of the Quality Control for Molecular Diagnostics (QCMD) organization was A.M. van Loon, a prominent member of the working group (QCMD, n.d.). This organization was established by the European Society of Clinical Virology (ESCV) in cooperation with the European Society of Clinical Microbiology and Infectious Diseases (ESCMID) and supported by the European Union Concerted Action on Virus Meningitis and Encephalitis, initiated by the British virologist G.M. Cleator of Manchester, UK. Nowadays, the QCMD operates as 
an independent International External Quality Assessment (EQA)/Proficiency Testing (PT) organization, providing wide-ranging quality assessment services, especially for diagnostic molecular testing for infectious diseases, to over 2,000 participants in over a hundred countries. A relatively large number of Dutch virologists played an important role in QCMD as part of the executive board or as scientific experts; among them were A.M. van Loon (chair, 2001-2016), J. Schirm, H.M.G. Niesters, Gerda T. Noordhoek and R. Schuurman.

\section{The Working Group for Molecular Diagnostics of Infectious Diseases (WMDI)}

The increasing applications of PCR and other molecular techniques in diagnostic virology led to the formation of a spin-off working group in 1997. Van Loon and Schuurman from UMC Utrecht, Niesters from Erasmus MC Rotterdam, and Gerda Noordhoek from the Regional Public Health Laboratory in Leeuwarden were the founders of the Working Group for Molecular Diagnosis of Infectious Diseases (WMDI) ${ }^{61}$ in the Netherlands. This new group had broader ambition than the mere detection of viruses, and aimed at the widespread application of molecular techniques across all branches of medical microbiology, including bacteriology and parasitology. There is a major crossover between this working group and the above-mentioned Dutch Working Group for Clinical Virology, as many individuals are members of both networks and joint annual meetings are organized.

\section{European societies and Dutch medical virology}

At the European and international level, the following societies served Dutch clinical virologists as meeting venues for the exchange of knowledge and expertise

\section{European Group for Rapid Viral Diagnosis}

The rise of rapid virus diagnostic techniques occurred worldwide, urging international initiatives to collaborate. Among others, P.S. (Philip) Gardner (UK), M. (Monica) Grandien (Sweden), C.M.V.P. Halonen (Finland), U. Krech (Switzerland), P. Leinikki (Finland), H. Schmitz (Germany), and J. van der Veen (the Netherlands) founded the European Group for Rapid Viral 
Diagnosis (EGRVD) in 1975. According to Gardner, even the WHO had an increasing involvement in rapid viral diagnosis (Gardner and McQuillin, 1980). In 1977, Gardner was invited to act as an adviser for the Provisional American Group for Rapid Viral Diagnosis, established by M. Chernesky, E. Lennette, K. McIntosh, S. Plotkin, C. Wilfert, and others. In 1978, its name changed to the Pan American Group for Rapid Viral Diagnosis (PAGRVD) to accommodate individual requests for membership originating from Mexico, Central America and South America (Chernesky, 200o). The first congress of the European Group took place at Amsterdam in 1977 and was organized together with the European Association against Virus Diseases (Gardner, 1978).J. van der Veen from Nijmegen was member of the organizing committee. This and subsequent meetings offered ample opportunity for international contact.

\section{European Association against Virus Diseases}

ESAVD was officially established on 19 May 1951 in Geneva, Switzerland, initially as the European Association against Poliomyelitis and Allied Other Virus Diseases (Union of International Associations, n.d.). It seems that the association was already active before its official establishment and organized the following conferences: 1946, Brussels; 1949, Paris; 1950, Amsterdam. In 1974, the name changed to European Association against Virus Diseases, or Association Européenne contre les maladies à virus.

\section{European Society for Clinical Virology}

The European Society for Clinical Virology (ESCV) is the successor of the aforementioned European Group for Rapid Viral Diagnosis and European Association against Virus Diseases, which merged into ESCV on 1 January 1997. ESCV is open to anyone interested in viruses as causes of disease in humans and animals, either as a (general) physician, paediatrician, veterinarian, infectious diseases specialist, (clinical) virologist or microbiologists, pure or applied, or just out of curiosity. Dutch members of the ESCV council were both from Groningen: J. Schirm (1998 to 2007, including president from 2001 to 2004), and Sytske Welling-Wester (1997 to 2005 as meetings secretary).

\section{European Society for Virology}

The European Society for Virology (ESV) is a non-profit organization officially founded on 30 October 2008. The need for such a society had 
already been felt much earlier, during the organization of the European Virology 2000 Congress that was held in Glasgow, Scotland, UK. A total of 25 national organizations collaborated for the organization of this meeting. Its success prompted the decision to organize a joint meeting covering all fields of virology every four years. Since 2008, ESV has provided a forum for scientists active in all aspects of virology, and organizes the quadrennial congresses in collaboration with ESCV. The stated aim of the society is to promote and stimulate the exchange of information and collaboration among individual scientists as well as among national and international associations of virology throughout Europe. To achieve these goals, ESV also organizes meetings and courses, offers fellowships and promotes education in virology at all levels. It represents the science, art and profession of virology to governmental and regulatory institutions of the European Union, the media and the general public.

\section{Waves of development and organization of clinical and fundamental virology}

In the beginning of the 1950s, the main first-wave advance in clinical virology occurred rather slowly, with the refinement of cell culture techniques. The realm of clinical virology appeared to lay at public health, preventive medicine, and university laboratories. Since the 1970s, and during the second wave, virology diagnostics, with new automated immunological assays and visualization techniques, expanded to general hospitals. University laboratories, the Central Laboratory of the Netherlands Blood Transfusion Service, ${ }^{62}$ and the laboratory of the Foundation of Cooperating Delft Hospitals (SSDZ) $)^{63}$ played a pioneering role in the advent of nucleic acid amplification techniques, resulting in a third wave of expansion of molecular virology diagnostics in general hospitals in the 1990s. In conclusion, the three technical waves drove medical virology into existence, as well as important medical services as a profession with numerous networks for discussion, education, training and exchange.

Concomitantly, in the 196os, virologists active in clinical as well as fundamental research, in the Netherlands and worldwide, felt the increasing need for independent meetings in their field. A working group for clinical

62 Centraal Laboratorium van de Bloedtransfusiedienst van het Nederlandse Rode Kruis (CLB), since 1998 Sanquin.

63 Stichting Samenwerkende Delftse Ziekenhuizen (SSDZ). 
virology as well as a rather independent Virology section within the General Microbiology Society was established in the Netherlands. The Clinical Virology Working Group also joined the Society of Medical Microbiology, an independent medical section of the General Microbiology Society. Although it seems that fundamental and clinical virologists engage sometimes into different or separate endeavours, their paths remain connected not only through their organizations and societies, but all the more by fruitful personal contacts and research collaborations.

In conclusion, we are compelled to highlight that, unlike in most other European countries, Dutch fundamental virology and medical virology remain joined through common organizations and societies. These two fields tend to function rather independently within the General Microbiology Society and the Society for Medical Microbiology, respectively. Although medical virologists may be outnumbered by bacteriologists in the NVMM or by fundamental researchers in the Virology section of the Royal Netherlands Society for Microbiology (KNVM), there are ample opportunities to meet and network through these organizations. Furthermore, judging by the number of Dutch virologists present in the executive boards or advisory councils of ESCV and ESV, we should be pleased with the excellent representation of Dutch clinical virology in international virology societies. 
